Cette rubrique est dirigèe par

Francis MEYER

Ingénieur général du G.R.E.F.

Conseil genéral

du Genie Rural des Eaux et des Forêts

30, rue Las-Cases

75007 PARIS

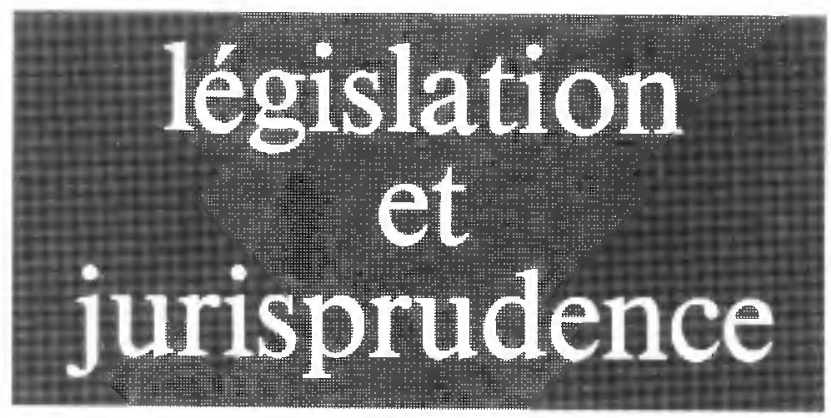

\title{
RÉPERTOIRE DES TEXTES LÉGISLATIFS ET RÉGLEMENTAIRES ET DE LA JURISPRUDENCE PUBLIÉS PENDANT LES MOIS DE JUIN ET JUILLET 1978
}

\section{CHASSE}

- Questions écrites - Assemblée nationale

Chasse (baux de chasse consentis par l'Office national des forêts)

$N^{\circ} 1485$ du 17 mai 1978, M. Lajoinie

(J.O. A.N. n 59 du 8 juillet 1978, p. 3851)

Chasse (réglementation)

$N^{\circ} 1734$ du 20 mai 1978, M. Braun

(J.O. A.N. $n^{\circ} 62$ du 29 juillet 1978, p. 4238)

\section{ÉCONOMIE FORESTIĖRE}

- Questions écrites - Assemblée nationale

Bois (Centre technique du bois)

$N^{\circ} 1968$ du 25 mai 1978, M. Maisonnat

(J.O. A.N. nº 62 du 29 juillet 1978, p. 4238)

- Questions écrites - Sénat

Exploitation rationnelle de la forêt

$N^{\circ} 28558$ du $1^{\text {er }}$ juin 1978, M. Coudert

(J.O. S. $n^{\circ} 55$ du 20 juillet 1978 , p. 2052)

\section{FONDS FORESTIER NATIONAL}

- Questions écrites - Assemblée nationale

Forêts (prêts du Fonds forestier national)

$\mathrm{N}^{\circ} 2623$ du 7 juin 1978, M. Braun

(J.O. A.N. n 60 du 15 juillet 1978, p. 3977)

\section{- Questions écrites - Sénat}

Crédits du Fonds forestier national

$N^{\circ} 26632$ du 8 juin 1978, M. Cluzel

(J.O. S. n० 55 du 20 juillet 1978, p. 2052) 


\section{OFFICE NATIONAL DES FORÊTS}

\section{- Arrêtés}

Arrêté du 9 mai 1978 relatif à l'approbation de dispositions prises en application des articles 36 et 37 de l'ordonnance réglementaire du $1^{\text {er }}$ août 1827 pour l'exécution du Code forestier (marteaux)

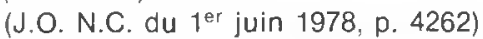

Arrêté du 12 mai 1978 relatif à la création d'une commission des marchés à l'Office national des forêts

(J.O. du 4 juin 1978, p. 4337)

\section{PROCÉDURE PÉNALE}

\section{- Lois promulguées}

Loi $n^{\circ} 78-788$ du 28 juillet 1978 portant réforme de la procédure pénale sur la police judiciaire et le jury d'assises (contrôle de la Chambre d'accusation sur les agents de police judiciaire) (J.O. du 29 juillet 1978, p. 2936)

\section{RÉGIME FORESTIER}

\section{- Projets et propositions de loi}

Proposition de loi relative à la gestion des biens des sections de commune (Assemblèe nationale $n^{\circ} 428$ )

\section{STRUCTURES FORESTIĖRES}

\section{- Décrets}

Décret $n^{\circ} 78-617$ du 31 mai 1978 pris pour l'application, dans le département de Tarn-et-Garonne, des dispositions de l'article 52-1 $\left(1^{\circ}\right)$ du Code rural

(J.O. du 2 juin 1978, p. 2248)

Décret $n^{\circ} 78-769$ du 12 juillet 1978 pris pour l'application des dispositions de l'article $52-1\left(2^{\circ}\right)$ du Code rural dans le département des Hautes-Alpes

(J.O. du 21 juillet 1978, p. 2896)

F. MEYER.

\section{JURISPRUDENCE}

\section{CONTENTIEUX ADMINISTRATIF}

Affaire R..., application cumulative de divers motifs prèvus par la loi pour justifier une interdiction de défricher $: 3^{\circ}$ ) existence des sources et cours d'eau, $6^{\circ}$ ) salubrité publique, $8^{\circ}$ ) équilibre biologique d'une région; arrêt du Conseil d'Etat statuant au Contentieux du 16 juin 1978.

La notion "d'équilibre biologique d'une région" d'une application rendue encore plus délicate depuis que s'y est ajoutee, la notion de "bien-être de la population " justifie en elle-même une interdiction de défricher, mais elle peut être appuyée par d'autres motifs reconnus par la loi tels que l'existence des sources et cours d'eau et la salubrité publique.

Monsieur R... avait adressé à l'Administration une demande d'autorisation de défricher 56 ha de bois sis dans l'Yonne à proximité d'un massif forestier ayant fait l'objet d'importants défrichements, le massif du Bas-Coin. Après enquête sur place et conformément à l'avis de la Section 
des Travaux publics du Conseil d'Etat, il lui fut opposé une décision de refus, le 9 juin 1975, basée sur la nécessité de protéger l'existence des sources et cours d'eau, la salubrité publique et l'équilibre biologique de la région $\left(3^{\circ}, 6^{\circ}\right.$ et $8^{\circ}$ de l'article 158 du Code forestier).

Monsieur R... déféra cette décision à la censure du Conseil d'Etat qui rendit le 16 juin 1978 l'arrêt suivant.

Considérant qu'aux termes de l'article 158 du Code forestier : "l'autorisation de défrichement peut être refusée lorsque la conservation des bois est reconnue nécessaire : ... $3^{\circ}$ ) à l'existence des sources et cours d'eau... $6^{\circ}$ ) à la salubrité publique... $8^{\circ}$ ) à l'équilibre biologique d'une région ";

Considérant que sans qu'il soit besoin d'ordonner l'expertise sollicitée, il ressort des pièces versées au dossier que le defrichement du Bois de Chanzy, situé dans le bassin-versant de l'Yonne, affecterait le régime de sources situées à une dizaine de kilomètres au nord-est; que les eaux recueillies au Bois de Chanzy alimentant plusieurs villages environnants et que la mise en culture de cette parcelle, par l'usage massif d'engrais qu'elle implique, provoquerait leur pollution, eu égard à la nature des sols constitués de calcaires très perméables; qu'enfin les bois dont il s'agit font partie du seul massif forestier important de la région et que leur maintien, eu égard au rythme des défrichements opérés dans les années récentes, doit être regardé comme nécessaire à l'équilibre biologique de cette région; que, dans ces conditions, le ministre de l'Agriculture a pu légalement, par l'ensemble de ces motifs, refuser l'autorisation de défrichement sollicitée;

\section{DÉCIDE :}

Article $1^{\text {er }}$. - La requête susvisée du sieur R... est rejetée.

Article 2. - Expédition de la présente décision sera transmise au ministre de l'Agriculture.

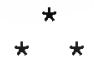

La Haule Assemblée a d'abord jugé inutile de recourir à une expertise, comme le demandait le requérant. II s'agissait en effet d'une région comprenant le Massif forestier du Bas-Coin et à l'occasion d'autres affaires de défrichement, la Section du Contentieux du Conseil d'Etat avait eu à connaître des études d'expert.

Des expériences de coloration à la fluorescéine, dans de petits cours d'eau de la région, avaient permis de constater une résurgence relativement rapide de ladite fluorescéine dans des sources à 13 kilomètres du point initial. Ces expériences citées par l'Administration expliquent pourquoi le Conseil d'Etat a admis que le régime des sources voisines pouvait être perturbé par un défrichement d'une cinquantaine d'hectares dans un massif installé sur des calcaires très perméables.

La Haute Assemblée, en se basant probablement sur les expertises antérieures a également estimé que la mise en culture des terres défrichées, par l'usage massif d'engrais, provoquerait une pollution dangereuse pour la salubrité publique des sources voisines, en raison de la perméabilité des sols calcaires.

Enfin le Conseil d'Etat a confirmé sa position sur l'équilibre biologique, en précisant que les bois dont le défrichement éfait demandé, étaient nécessaires à l'équilibre biologique de la région, car ils appartenaient au seul massif important de ladite région, et que leur maintien, en raison de la cadence des défrichements récents, était indispensable.

La netfe séparation dans l'argumenfation du Conseil d'Etat, de la justification des différents motifs d'interdiction de défricher, permet d'estimer que la Haute Assemblée n'englobe pas dans l'équilibre biologique, la profection des sources et la salubrité publique.

Toutefois depuis qu'à l'équilibre biologique est ajoutè le bien-être de la population (mudification apportée par la loi sur la protection de la nature du 10 juillet 1976), cefte nouvelle notion pourrait englober d'autres motifs de refus prévus par l'article 158 du Code forestier.

\section{GAUTRET}

